\title{
DOS MODELOS DE UNIVERSIDAD EN LAS NOVELAS DE DAVID LODGE
}

M.' Teresa GiberT-Maceda

UNED

En los debates actuales sobre política universitaria frecuentemente se alude a las modalidades británica y americana como los dos sistemas organizativos fundamentales de la enseñanza superior en el mundo. Situándonos en un plano ideal, resulta fácil definir tales modelos. Más complicado parece alcanzar un acuerdo cuando se trata de citar nombres concretos que ejemplifiquen los arquetipos, pues cada una de las universidades de ambos países manifiesta unas peculiaridades propias susceptibles de multiplicar el número de variantes. Además, la experiencia individual difiere en la práctica y, por consiguiente, suscita percepciones antagónicas de un mismo objeto de conocimiento. Sin embargo, el marco de una obra literaria puede aportarnos una fórmula conceptual que satisfaga simultáneamente la dimensión abstracta y la concreta. Un escritor contemporáneo nuestro, que a menudo elucubra sobre las relaciones entre la vida ficticia y la real, nos ofrece en sus novelas dos prototipos capaces de satisfacer tantas condiciones: las universidades de Rummidge y de Euphoria.

El hecho de que, para describir tales instituciones, David Lodge se haya basado respectivamente en las Universidades de Birmingham y de California no implica que la correspondencia entre ellas sea exacta. Recordemos la respuesta negativa del novelista a quien le preguntaba si solía inventar las situa- 
ciones, anécdotas y personajes, o bien si los tomaba de su experiencia personal $^{1}$. Aquí también es posible aplicar la tercera alternativa que sugería el novelista al admirador perplejo. Las Universidades de Rummidge y de Euphoria ni son exclusivamente el fruto de la pura imaginación del artista, ni son el fiel retrato de los dos centros de enseñanza citados, sino que en ellas se funden una vez mas la ficción y la realidad. Además, el humor recorre todas estas páginas bajo diversas formas, que van desde la sutil ironía hasta la sátira mordaz, pasando por el ingenioso juego de palabras y el chiste fácil. Hay, pues, unos elementos caricaturescos que acentúan con permanente comicidad los rasgos típicos de una universidad provinciana británica frente a la otra, situada entre las mejores de los Estados Unidos.

David Lodge se doctoró por la Universidad de Birmingham, en cuyo Departamento de Inglés fue profesor desde 1960 hasta que en 1987 se retiró de la cátedra de Literatura Inglesa Moderna para dedicarse por entero a escribir ensayos y novelas, conservando un nombramiento honorífico. En cuanto a sus estancias en Estados Unidos, debemos resaltar dos visitas. Gracias a una Harkness Commonwealth Fellowship, pasó la primera parte del curso 1964-65 en la Brown University de Providence (Rhode Island) y, en marzo de 1965, inició un recorrido de tres meses por el país, un viaje apasionante hacia el Oeste con destino final en San Francisco. Algunos años después, en 1969, volvió como profesor visitante a la Universidad de California, Berkeley.

El propio Lodge ha aludido en múltiples ocasiones al descubrimiento suyo de América o, con mayor propiedad debiéramos decir, «descubrimiento suyo en América», pues consistió en descubrirse a sí mismo en un ambiente nuevo para $\mathrm{el}^{2}$. En Rhode Island escribio The British Museum Is Falling Down con una rapidez insólita, en parte porque estaba libre de cualquier obligación docente y en parte porque deseaba que nadie se le adelantase tratando el tema de la novela, pero también por una tercera razón: «the generally stimulating and liberating effect of the American experience» ${ }^{3}$.

En América, David Lodge encontró no sólo el tiempo y el estado de ánimo propicios para componer su primera novela de carácter experimental, sino también un abundante material para otras tres novelas de la misma índole: Changing

1 David Lodge: «The Novel Now: Theories and Practices», Novel, XXI, 2-3 (WinterSpring, 1988), pp. 130-1; reprod. en After Bakhtin, London \& New York, Routledge, 1990 , pp. 11-24.

2 Véase el ensayo de DAvid LodGe: «The Bowling Alley and the Sun, or How I Learned to Stop Worrying and Love America», The Southern Review, 1968; reprod. en Write On. Occasional Essays 1965-1985 (1986), Harmondsworth, Penguin, 1988, pp. 3-19.

3 DAVID LodoE: «An Afterword» (1980), The British Museum Is Falling Down (1965), Harmondsworth, Penguin, 1983, p. 163. 
Places (1975), Small World (1984) y Nice Work (1988). En ellas Lodge desarrolla el llamado «subgénero» de la novela académica, que él sitúa esencialmente en las Universidades de Rummidge y de Euphoria. Como la acción de Changing Places se inicia el 1 de enero de 1969, la de Small World en abril de 1979 y la de Nice Work el 13 de enero de 1986, los lectores pueden observar tres momentos diferentes en la vida de las dos Universidades y, al mismo tiempo, pueden apreciar las transformaciones que ambas sufren a lo largo de diecisiete años de existencia en el mundo de la ficción.

Los nombres de Rummidge y de Euphoria han sido inventados por el novelista, quien indicó un origen metonímico para el primero y una relación metafórica para el segundo ${ }^{4}$. En efecto, Rummidge evoca el verbo «rummage» y la expresion «rummage sale». En Changing Places, cuando el Profesor Swallow menciona el nombre de la Universidad de Rummidge, Mrs. Zapp cree haber escuchado «Rubbish» y así lo hace notar enfáticamente, riéndose de su propia bro$\mathrm{ma}^{5}$. Si la denominación de Rummidge tiene connotaciones negativas por su asociación con «rummage» y con «rubbish», Euphoria en cambio nos sugiere un ambiente de alegría y bienestar. Mucho antes de publicar Changing Places, Lodge emplé repetidamente la palabra «euphoria» refiriéndose a su experiencia americana ${ }^{6}$, e incluso comentó que se había divertido con un amigo suyo creando, en un supuesto Euphoric State de la costa oeste, una universidad mítica que concedería créditos por asignaturas tales como «baños de sol», «surfing» y «esquí acuático» ${ }^{7}$.

Dado que la estructura de Changing Places se basa en una extensa serie de oposiciones binarias, el contraste entre las universidades de Rummidge y de Euphoria es evidente desde el comienzo y se acentúa a lo largo de la narración. Ya el subtítulo de la obra, «A Tale of Two Campuses», anuncia que la acción se va a desarrollar en dos escenarios diametralmente diferentes. Las dos Universidades tienen establecido un programa anual de intercambio de profesores, que se viene realizando durante la segunda mitad de cada curso para celebrar una curiosa coincidencia arquitectónica. Ambas cuentan con una réplica de la Torre de Pisa (aunque no inclinada), que en América ha sido ostentosamente construida de mármol blanco y multiplicando por dos su tamaño, mientras que

4 DAVID LODGE: «Modernism, Antimodernism and Postmodernism», Working with Structuralism, London, Routledge \& Kegan Paul, 1981, p. 16.

5 DAvid LoDGE: Changing Places (1975), Harmondsworth, Penguin, 1983, p. 81.

6 DAvD LODGE: «Choice and Chance in Literary Composition: A Self-analysis», reprod. en The Novelist at the Crossroads, London \& New York, ARK Paperbacks, 1986, p. 81.

7 DAVID LODGE: «The Bowling Alley...», ibid., p. 7. Lodge redactó este ensayo un año después de volver de su primera visita a los Estados Unidos y lo reviś en 1968. 
en Inglaterra se ha empleado un modesto ladrillo rojo y se ha conservado la escala original. La mención de los materiales y las dimensiones de los edificios es uno de los numerosos detalles mediante los cuales el autor pone de relieve significativamente la disparidad entre dos mentalidades, dos actitudes, dos formas de vida.

Los profesores Philip Swallow y Morris Zapp, cuyas características físicas y psíquicas son divergentes, van a ser los beneficiarios del intercambio del año 1969. Aunque ambos personajes no pueden equipararse en cuanto a valía profesional, una serie de circunstancias fortuitas colocan a cada uno de ellos en el lugar del otro durante algunos meses. El británico Philip Swallow se interesa por una gran variedad de temas; pero como carece de voluntad y ambición, nunca consigue especializarse en alguno de ellos y, por consiguiente, es absolutamente desconocido fuera de su departamento. En cambio, el americano Morris Zapp goza de un prestigio universal, porque se ha distinguido desde su juventud por el número y la calidad de sus publicaciones (colaboraba en la revista P.M.L.A. siendo estudiante y era autor de cinco libros a los treinta años). Ahora bien, como a menudo sucede, las razones personales prevalecen sobre las académicas cuando se toman decisiones de este tipo. El mediocre profesor inglés tiene la inmerecida suerte de viajar hasta un auténtico paraíso terrenal californiano, mientras que el brillante profesor estadounidense va a sufrir incomodidades sin cuento en una modesta universidad provinciana del norte de Inglaterra. A Swallow ni siquiera se le habría ocurrido solicitar el ansiado puesto docente en América, pero el director de su departamento se lo ofrece para evitar una situación embarazosa en Rummidge: no conviene que Swallow esté presente cuando se conceda un importante ascenso a un compañero más joven y con más méritos que él. Por el contrario, Zapp podría haber obtenido un cargo relevante, pero la precipitación con la que decide abandonar temporalmente Euphoria le obliga a aceptar la única oferta disponible. En consecuencia, desde el principio, el entusiasmo de Swallow ante este regalo de la fortuna contrasta con el disgusto $\longrightarrow$ la resignación - de Zapp ante un futuro tan poco prometedor.

Para el oscuro Swallow, la perspectiva de pasar un semestre en Euphoria supone una magnífica oportunidad en los planos personal y profesional, con una clara preponderancia del primero sobre el segundo. El profesor británico conserva un espléndido recuerdo de una estancia anterior en el país donde, tras una etapa difícil en Harvard, contrajo matrimonio con su novia inglesa Hilary. Como la beca de Swallow requería viajar (condición semejante a la beca que recibió Lodge en 1964-65), los recién casados disfrutaron de una maravillosa luna de miel subvencionada. Tras una temporada de intenso placer y tranquilidad absoluta en el agradable clima de Euphoria, el retorno al frío, la lluvia y las 
estrecheces de Inglaterra resultó traumática para los jóvenes Philip e Hilary. Ahora, muchos años después, Philip Swallow vuelve a Euphoria con la secreta esperanza de recuperar algo de aquel paraíso perdido al que esta vez va a llegar solo. Así pues, la estancia en Euphoria también implicará una cierta liberación de sus tediosas obligaciones familiares, porque su mujer e hijos quedan en Inglaterra.

Las razones por las que Zapp se dirige a Rummidge son muy distintas. Mediante esta breve separación de su familia, Morris trata de evitar un inminente segundo divorcio, confiando en que la distancia reparará los desastrosos efectos de su convivencia matrimonial con Desirée. En el caso del profesor americano no existe ningún motivo que le atraiga a Rummidge, sino únicamente el deseo de huir de un conflicto familiar. Zapp no siente afecto alguno -ni siquiera respeto- por los británicos, a los que ha tenido la desgracia de padecer en América. Siempre le han exasperado los profesores ingleses que visitan Euphoria y que en las fiestas se atiborran de canapés, se beben toda la ginebra y nunca cesan de hablar, con voces chillonas, sobre las diferencias entre los sistemas educativos británico y americano, dando a entender su desprecio por el segundo. Además, le irrita la condescendencia con la cual los (a su juicio) incompetentes profesores británicos tratan a sus eminentes colegas americanos, en unos ensayos plagados de errores e inexactitudes. Por eso Zapp llega a Inglaterra sin alicientes, convencido de que va a encontrarse solo y aburrido.

El contraste entre las Universidades de Rummidge y de Euphoria se pone de manifiesto por los comentarios del narrador, las diversas situaciones y las observaciones que los dos protagonistas van comunicando por cartas a sus esposas. Por ejemplo, es patente la amable acogida americana que halla Swallow, frente al gélido recibimiento británico que la facultad dispensa a Zapp. Con respecto a las instalaciones de los edificios universitarios, a Zapp le sorprende que los profesores ingleses trabajen en despachos bien amueblados, amplios y hasta cierto punto lujosos, comparados con los más modestos y funcionales despachos de los profesores norteamericanos; su extrañeza es aún mayor cuando considera la incomodidad de las casas inglesas comparada con el confort de las americanas. Zapp tampoco comprende la forma de impartir enseñanza mediante tutorías, ni la falta de especialización de los profesores británicos, ni los privilegios de los catedráticos, ni el carácter vitalicio de los puestos, ni los métodos que se emplean para promocionar a los docentes. Por su parte, aunque Swallow siente una gran admiración general por América, añora algunos aspectos de la vida universitaria de su país natal; por ejemplo, le aterra la competitividad de la jungla académica estadounidense en la cual parece que los débiles no pueden sobrevivir. Por el contrario, Zapp - que está afrontando un 
cúmulo de dificultades en Inglaterra - hacia el final reconoce que nunca se había sentido tan poco amenazado con respecto a su carrera, pues ha pasado cinco meses en una universidad en la cual jamás se expulsa a un profesor por incompetencia, sino únicamente en circunstancias excepcionales por algún escándalo grave.

El ambiente de la Universidad de Euphoria en 1969 se asemeja al que David Lodge describe en sus ensayos sobre la Universidad de California, en la cual él estuvo trabajando a la sazón. Así, las revueltas estudiantiles de la novela están directamente inspiradas por las que él conoció allí; en concreto, el incidente sobre el Jardín del Pueblo de Changing Places tuvo su origen en las luchas por el Parque del Pueblo en Berkeley, y la figura del Gobernador Ronald Duck está modelada cómicamente sobre la del entonces Gobernador Ronald Reagan ${ }^{8}$.

Casi diez años después de haberse interrumpido la acción de Changing Places - una novela sin final propiamente dicho- se inicia la acción de Small World en la Universidad de Rummidge. Con otros nuevos personajes, reaparecen los dos protagonistas de aquella obra, viajando ahora incesantemente por el «campus global» creado gracias a las nuevas tecnologías. «The day of the single, static campus is over», exclama con entusiasmo Morris Zapp ${ }^{9}$. En cierto sentido, el profesor americano tiene razón: los investigadores se reúnen en congresos y cada vez se comunican con mayor facilidad y rapidez. Sin embargo, como el acceso a los nuevos medios varía según la capacidad económica de cada institución, las diferencias tienden a acentuarse. Así, mientras que sólo 57 personas asisten al modesto congreso de Rummidge, 10.000 participantes se congregan en el de la $M L A$. Mientras que los profesores americanos cuentan con financiación para todos sus desplazamientos, los británicos carecen de buenas subvenciones para costear su asistencia a congresos celebrados dentro del Reino Unido (aunque, por una anomalía del sistema, les resulta comparativamente más fácil obtener fondos para trasladarse al extranjero).

En Small World no volvemos a visitar Euphoria, pero contemplamos a Morris Zapp viajando por el planeta y, a través de él, percibimos algunos aspectos de su universidad, su opulencia en particular. En cuanto a la Universidad de Rummidge, el congreso que allí organiza Swallow nos permite comprobar que su nunca glorioso campus va declinando: los edificios construidos

8 DAvid Lodge: «The People's Park and the Battle of Berkeley» (1969), Write On, ibid., pp. 17-27. El nombre de Ronald Duck (basado sobre el de Donald Duck, el «pato Donald» de Disney) evoca humorísticamente la carrera cinematográfica del que llegaría a ser Presidente de los Estados Unidos de América.

9 DAvD LODGE: Small World (1984), Harmondsworth, Penguin, 1985, p. 63. 
precipitadamente en la década anterior soportan mal el paso del tiempo. En conjunto, la situación de la Universidad de Rummidge en 1979 ha cambiado poco con respecto a 1969: los catedráticos mantienen sus antiguos privilegios, los profesores mediocres ascienden, los investigadores británicos siguen despreciando a sus colegas americanos...

En líneas generales, Small World presenta ambas universidades con los mismos rasgos que las caracterizaban en Changing Places. En el caso de Rummidge, la gran transformación se registra en Nice Work, cuya acción se sitúa en 1986, cuando ya se hacen notar plenamente los efectos de la crisis económica. Philip Swallow, aunque haya llegado a ser Decano gracias a un sistema que promociona a los más inútiles, ya no consigue que su universidad le costee sus ansiados viajes. Sin poder asistir a congresos, sin tiempo para leer ni escribir, pasa largas horas tratando de resolver los acuciantes problemas administrativos de su facultad. En Rummidge se suceden las huelgas en protesta por las restricciones del Gobierno conservador; las medidas de ahorro se generalizan y se llevan a extremos ridículos (reciclaje de sobres usados, recomendaciones acerca del uso de siglas para economizar papel y tiempo de mecanografiado, supresión del mecanismo automático de limpieza en los aseos...). Los profesores se enemistan entre ellos discutiendo sobre la reforma del plan de estudios, tratando de defender sus propios intereses, amenazados tanto por una política de unificación como por otra de diversificación, pues ambas pueden conducirles a la ruina. Los despidos se multiplican y la jubilación anticipada elimina de la corporación a muchos miembros activos. En contraste con tal declive, las noticias sobre la floreciente Universidad de Euphoria indican que todavía quedan lugares en el mundo donde los investigadores se sienten estimulados, disfrutan de becas, viajan, disponen de los últimos avances tecnológicos, comentan las novedades bibliograficas... Dado que la poderosa Universidad americana abre sus puertas a los mejores docentes británicos, la fuga de cerebros es inevitable, con el consiguiente empobrecimiento del más pobre y el progresivo enriquecimiento del más rico. En cuanto a la responsabilidad del desastre en el Reino Unido, David Lodge culpa abiertamente a Mrs. Thatcher por su política destructiva en materia de educación superior.

Otras novelas de Lodge también nos presentan las divergencias entre determinados aspectos de la sociedades británica y americana, sin limitarse a la vida académica. Por ejemplo, Out of the Shelter compara las formas de vida de ingleses y americanos durante la posguerra; How Far Can You Go? contrapone dos maneras de entender el catolicismo. En The British Museum Is Falling Down el autor describe a los «earnest, efficient Americans, humming away like dynamos, powered by Guggenheim grants» leyendo en la Biblioteca Británica, 
que un ingenuo investigador estadounidense quisiera comprar para reconstruirla - piedra a piedra - en Colorado ${ }^{10}$.

En la última novela de David Lodge el campus universitario ya no ocupa el primer plano, aunque se percibe a veces como telón de fondo a través de la presencia de algunos profesores. El protagonista de Paradise News, Bernard Walsh, es un ex-sacerdote que ha encontrado un modestísimo puesto de trabajo en Rummidge. La Universidad ha conseguido sobrevivir a los peligros que la acechaban gracias a la implantación de un régimen abierto que no sólo le permite recibir a todo tipo de alumnos, sino incluso acomodar en su claustro a un teólogo escéptico. Mediante un extenso símil de gran comicidad, los «South Rummidge Colleges» se comparan con un «supermercado religioso», con las ventajas y los inconvenientes de dicha fórmula comercial: una ingente cantidad y variedad de productos para satisfacer cualquier gusto, pero también el riesgo de saciar y aburrir a los clientes junto con la posibilidad de convertirlos en seres indecisos o apáticos ${ }^{11}$.

Lo más curioso de Paradise News con respecto al tema que nos ocupa es el que por vez primera Lodge nos ofrezca una visión bastante agradable de Rummidge en contraste con un panorama negativo de la sociedad americana y una actitud de censura ante el influjo que ésta viene ejerciendo sobre todo Occidente. En Changing Places (p. 13), la urbe industrial inglesa aparecía rodeada por autopistas, líneas férreas y canales malolientes; en Nice Work (p. 150) se había caracterizado por la oscuridad, la lluvia, la humedad y el frío, factores climáticos responsables de causar varias enfermedades entre los habitantes. Por el contrario, el final de Paradise News nos muestra un idílico paisaje de esa misma ciudad contemplada durante un hermoso día de octubre a través de los ojos de un protagonista enamorado y feliz (p. 357). En esta reciente novela ya no aparece el maravilloso entorno de la universidad californiana, pues el campus americano está representado por Boston y Hawai. De Boston se evoca el frío invernal y los catarros que éste provoca (p. 175). Hawai aparece como un paraíso falso, artificialmente modelado según los intereses comerciales de unos especuladores que sólo se rigen por móviles económicos, sin respeto alguno hacia los espacios naturales. El autor pone de relieve la manipulación que sufren los turistas, atraídos por reclamos publicitarios de sol, mar y tranquilidad, al llegar a un destino donde el calor es insoportable, la atmósfera está contaminada y las playas abarrotadas de bañistas. Lo que los ilusos viajeros descono-

10 David Lodge: The British Museum Is Falling Down (1965), Harmondsworth, Penguin, 1984 , pp. 45 y 151.

11 David Lodge: Paradise News (1991), London, Penguin, 1992, p. 35. 
cen es que Waikiki se ha transformado en uno de los lugares con mayor densidad de población del mundo entero (p. 163), razón por la cual sus sueños deberían desvanecerse, aunque un extraño mecanismo mental les impedirá ser plenamente conscientes del fraude.

David Lodge, en sus novelas anteriores, venía realizando una suave crítica de la vida americana, mediante leves alusiones a la ingenuidad y al derroche, que casi podrían interpretarse como muestras de un temperamento inocente y generoso. En cambio, a través de Paradise News, se agudiza la sátira dirigida contra una sociedad de consumo insensible, materialista, despilfarradora y superficial. Hawai, situado geográficamente en el extremo de América, parece haberse convertido en una América llevada al extremo: el paraíso que siempre ha estimulado la imaginación de los estadounidenses. Pero el resultado es una falacia. Las apariencias engañan. El paraíso es ilusorio. La Universidad de $\mathrm{Ha}$ wai, desde lejos considerada como un centro de diversión más que de trabajo, acaba decepcionando y aburriendo a todos sus miembros, que se esfuerzan por disimular el hastío y la nostalgia ante sus colegas (p. 177).

El hecho de que Lodge siga escribiendo y publicando impide el establecimiento de unas conclusiones definitivas con respecto a la cómica confrontación en su narrativa de los dos modelos universitarios. Cabe la posibilidad de que complete o modifique los conceptos ya expresados. A través de varios ensayos, en particular los reunidos en la colección Write On, el autor matiza sus opiniones e incluso cuestiona algunas idea expuestas - quizás de una manera excesivamente simplista - por sus personajes de ficción, en particular con respecto a la aparente meritocracia de la vida académica americana y sobre el mito de "publicar o perecer»" 12 . Pero tales puntualizaciones no caben en sus novelas, a través de las cuales Lodge traza una serie de sugerentes retratos, o caricaturas, de dos universidades imaginarias evolucionando a lo largo del tiempo con el mismo ritmo que sus equivalentes en la vida real.

12 David LodGE: «Strictly Confidential» (1975), Write On, ibid., pp. 41-4. En esta reseña sobre el libro de L. S. LewIS, Scaling the Ivory Tower: Merit and Its Limits in Academic Careers, Lodge resalta la estadística según la cual, en la mayoría de las universidades norteamericanas, más del $90 \%$ de las publicaciones son obra de menos del $10 \%$ de los miembros de cada facultad. 